\title{
The Role of Category Labeling in Categorization and Evaluation of New Products
}

\section{Pinar YILDIRIM iD a}

a Bilgi University, School of Applied Sciences, İstanbul, Turkey. pinar.yildirim@bilgi.edu.tr

\begin{tabular}{|c|c|}
\hline ARTICLE INFO & ABSTRACT \\
\hline $\begin{array}{l}\text { Keywords: } \\
\text { New Product } \\
\text { Category Label } \\
\text { Categorization } \\
\text { Attitude } \\
\text { Purchase Intention }\end{array}$ & $\begin{array}{l}\text { Purpose - The purpose of this study is to analyze how consumers react to new products that do not } \\
\text { fit into any existing product categories in their minds and how the category label provided for the } \\
\text { new product helps them understand and categorize it. It intends to discover how consumers' } \\
\text { attitudes, purchase intentions, and expected benefits from a new product are shaped when they can } \\
\text { categorize the product versus when they cannot. The drink "cider" is chosen as the new product } \\
\text { subject to the study. Although the imaginary cider brand in the study contains three percent alcohol, } \\
\text { it is labeled either as a soft drink or an alcoholic drink. Another aim of the study is to test whether } \\
\text { consumers' categorization decisions are affected by the labels and cues provided in the } \\
\text { advertisements although more suitable categorizations are possible. }\end{array}$ \\
\hline $\begin{array}{l}\text { Received } 19 \text { February } 2020 \\
\text { Revised } 13 \text { July } 2020 \\
\text { Accepted } 10 \text { November } 2020\end{array}$ & $\begin{array}{l}\text { Design/methodology/approach - }(2 \times 2) \text { ANOVA is run on } 350 \text { participants. Category label is } \\
\text { manipulated with a } 2 \text { (soft drink schema ad with no label indicated-alcoholic drink schema ad with } \\
\text { no label indicated }) \text { x } 2 \text { (soft drink schema ad with soft drink label indicated-alcoholic drink schema } \\
\text { ad with alcoholic drink label indicated) between-groups design. }\end{array}$ \\
\hline \multirow[t]{2}{*}{$\begin{array}{l}\text { Article Classification: } \\
\text { Research Article }\end{array}$} & $\begin{array}{l}\text { Findings - When faced with a new product, consumers categorize the product in the direction of } \\
\text { the label provided in the advertisement and away from other more likely categorizations. Although } \\
\text { the cider brand contains three percent alcohol, when it is labeled as a soft drink, it is categorized as } \\
\text { a soft drink. Consumers who are uncertain about cider's product category showed lower attitude } \\
\text { towards the product and purchase intention scores than consumers who are more confident about } \\
\text { their category decisions. }\end{array}$ \\
\hline & $\begin{array}{l}\text { Discussion - When a new product is introduced into the market, the product's marketing } \\
\text { communications should clearly define the product, its product category, its benefits, and usage } \\
\text { situations. The label and cues given in the advertisements will help consumers to place the product } \\
\text { into a category indicated by advertisements. Providing a label also helps consumers to have a } \\
\text { positive attitude towards the product and increases its chance of trial. }\end{array}$ \\
\hline
\end{tabular}

\section{Introduction}

The categorization process can be defined as analyzing the ways consumers organize their thinking about specific product alternatives (Gutman, 1982). According to Mervis and Rosch (1981), a category is formed when two or more separate objects or events are labeled under the same name or have the same impact on different objects.

Both the marketing and psychology literature analyze how people organize knowledge in memory and how they interpret and group novel items (Cohen and Basu, 1987; Loken and Ward, 1990).

Rosch (1999) suggests that there are two basic principles for the formation of categories. The first principle indicates that the task of category systems is to get maximum information about our environment while using our finite resources as frugal as possible. It is a heuristic, which consumers opt to use in decision making as well when they are faced with situations that require excessive cognitive processing (Shiv and Fedorikhin, 1999). It also helps to reduce the dissimilarities among stimuli and organize them around behaviorally and cognitively consistent groups (Rosch, 1999). However, using categorization as a shortcut can also induce prejudice on some occasions (Dovidio et al., 2017).

The second principle is based on the notion that we as humans need structured information to make sense of the perceived world. Categories map the perceived world structure better than arbitrary and unpredictable attributes. According to Bruner et al., (1972) and Lingle et al., (1984) by categorizing objects and events, our 
information processing efficiency and cognitive stability are improved. Such organized knowledge structures help us to make sense of new items/events, so that we can make use of the guiding commonalities instead of irrelevant uniqueness when drawing inferences about attributes and making evaluative judgments (Cohen and Basu, 1987).

Barsalou (1983) suggests that sometimes "people construct ad hoc categories to achieve goals". He indicates that products can also be categorized to fulfill a certain goal. If you have a goal of losing weight, you may choose to eat yogurt or steamed vegetables or fruits, all belong to different taxonomic categories, for dinner. When Kellogg launches Special K- bar as a low-calorie snack, it is not competing in the regular snack category but in the diet products category, which may include low-fat yogurts, fruits, and so on.

A different view named as probabilistic view suggests that categories are "fuzzy" or ill-defined and that categories are organized around a set of properties or clusters of correlated attributes that are characteristic or typical of category membership (Medin et al., 1987). This fuzzy set theory, suggests that the boundaries between members and nonmembers of a set are not clear (Mela and Lehmann 1995; Viswanathan and Childers 1999). Membership in probabilistic categories is graded, rather than all or none, and the better or more typical members possess more characteristic properties than the poorer ones. For example, "orange juice" is a better example of a "juice" category than "pomegranate juice" (Barsalou 1983).

Categorization decisions also affect information processing, product evaluation, and choice (Sujan 1985; Sujan and Dekleva 1987; Meyers-Levy and Tybout 1989). Past research shows that categorization has a strong effect on evaluation (Sujan 1985; Moreau, Markman and Lehmann 2001) and when consumers process information about products, categorization comes before evaluation. Other studies state that category identification and evaluation are intertwined (Cohen and Basu 1987). According to Weiss and Johar (2013), people categorize products by using personal self, and ownership of a product can be used as a reference for egocentric categorization. When consumers see the traits of themselves in products, they evaluate products accordingly.

There are several aims of this study. One of them is to understand how category decisions take place when consumers are faced with a new product that doesn't belong to any existing category. A beverage called cider, which is unknown to the Turkish market is chosen as the unit of study. Cider is defined both as "an alcoholic drink made from apples" and also as "juice from crushed apples used as a drink or to make vinegar" (www.dictionary.cambridge.org, 2020). Cider is not sold in the Turkish market and out of the 350 people who participated in this study only five of them have heard of cider before. Some of the questions that this study tries to find answers for are: If some cues are provided in the advertisements and an explicit label is given about the nature of the product, in what way will it affect individuals' category decisions? When consumers are provided with a soft drink label for an alcoholic beverage, is it possible to change their categorization decisions in the direction of the label?

In addition, the study attempts to discover whether the benefits expected from cider will depend on its perceived product category. It is anticipated that when cider is categorized as a soft drink, participants will expect cider to have the attributes and benefits of a soft drink. Similarly, if participants categorize cider as an alcoholic drink, they will expect the same benefits from cider as they do from an alcoholic beverage.

The other aim of the study is to understand the relationship between category confidence and attitude towards the product and purchase intention. How will consumers' attitudes toward the new product and purchase intention change when they are more confident about their categorization decisions as opposed to when they are less confident?

\section{Categorization of New Products}

Most of the categorization research on new products examines how consumers perceive, learn about, and form preferences about really new products that have both similarities and dissimilarities to existing product categories (Moreau, Markman and Lehmann 2001; Moreau, Lehmann, Markman 2001; Gregan-Paxton et al., 2002).

Analogical learning theory helps researchers to understand the process of how consumers use their existing knowledge to make sense of new products. An analogy is simply defined as the information transfer from a familiar domain (base) to a new domain (target) to make sense of this new domain (Gentner 1983; Gregan- 
Paxton et al. 2002). "An iPad is like a PC" denotes a mapping from the PC to the iPad. The iPad is the domain being scrutinized and the PC is the domain that acts as a basis of knowledge for the comparison. Thus, the iPad is called the target and the PC is called the base.

Sometimes the shape of the bottle of a soft drink can act as a cue that helps the categorization process (Arboleda and Arce-Lopera, 2015) and sometimes consumers use personal self as a reference category for a product.

The unit of study in this research as a new product is "cider". Although cider has been sold in Europe or the US for many years, no such product exists in the Turkish market and it doesn't fit into any existing beverage category. It lies on a thin line between a soft drink and an alcoholic drink. In some countries such as Japan, Korea, and Pakistan, cider is sold as a carbonated soft drink whereas, in others such as England, Germany, France, Ireland, and Finland, it is sold as an alcoholic drink, the alcohol percentage varies from 2 percent to 8.5 percent. In the United States and Mexico, it is sold both as a soft drink and also as an alcoholic drink (https://www.alliedmarketresearch.com/cider-market, 2019). Thus, it is fair to assume that cider cannot be automatically categorized as a soft drink or as an alcoholic drink and yet knowledge from these two categories can be used to form a preliminary presentation of the new product. The fictional cider brand in our study contains 3 percent alcohol which is similar to the amount in light beer. This percentage is chosen specifically to ensure that cider contains a noticeable degree of alcohol but not too much that will make it impossible to be categorized as a soft drink.

In this study, cider will be the "target" as it is the new product that consumers don't have enough information about, and soft drink or alcoholic drink categories will be employed as the" base", the familiar categories where information transfer will commence.

\section{Hypotheses}

This study adopts the hypotheses from a previous work of Moreau, Markman, and Lehmann (2001) that investigates the effect of categorization on new product evaluation.

Past studies in categorization literature investigate the use of categories in making inferences about new instances (Murphy and Ross, 1994; Thomas 1998; Ziamou and Gregan-Paxton, 1999). Research in knowledge transfer proposes that knowledge from a known, existing category is transferred to an unknown target in three stages: access, mapping, and transfer (Gentner, 1989). In the first stage, a familiar category has been accessed in the consumer's mind, and in the second stage properties of that category are mapped onto properties of the target by one-to-one correspondence. In the last stage, additional information about the accessed category is transferred to the target with the initial mappings serving as pathways for the additional knowledge (Moreau, Markman and Lehmann, 2001; Moreau, Lehmann, Markman 2001).

Because of new products' unknown nature, when facing a really new product consumers most probably will not be able to facilitate relevant knowledge structures from memory. Marketers can affect categorization-based transfer if they provide a "category label" that proposes the new product's category membership (GreganPaxton et al., 2002). Thus, the first two hypotheses are:

Hypothesis 1: When faced with a new product, consumers will categorize the new product in the direction of the cue provided in the advertisement and away from other more likely categorizations.

Also, consumers are expected to have higher degrees of category confidence once they are provided with a label. So, the second hypothesis is proposed:

Hypothesis 2: When consumers are cued with a label, there will be an increase in their categorization confidence scores.

When exposed to the category label, subjects are expected to induce extensive knowledge transfer based on the cued category. So when a novel product is associated with an existing schema through analogy, the comparable features between the base domain and the new product are specified and the attributes of the new product are organized accordingly (Gregan-Paxton et al., 2002).

In this study, the participants exposed to soft drink (alcoholic drink) label are expected to categorize cider as a soft drink (alcoholic drink), and then transfer the attributes of soft drinks (alcoholic drinks) to cider. Thus, 
the expected benefits from cider are anticipated to be in line with the soft drink (alcoholic drink) category. This leads to the following hypothesis:

Hypothesis 3: Consumers' performance expectations of the new product will be in line with the performance of the products that they think belong to the same categorization.

If consumers cannot achieve analogy-based transfer with certainty their ability to make more extensive mappings from base to the target domain may be impaired (Gentner, 1989; Gregan-Paxton and John, 1997). It can be assumed that if subjects are not certain about which category to access, this situation may inhibit their ability to map and transfer the information from the base category to the new target. That is if they are not confident with their categorization decisions they may have more difficulty in constructing the performance expectations for the new product. Moreau, Markman, and Lehmann (2001), suggested that consumers' preferences for a new product will be affected by their expectations from that new product. That means higher expectations will lead to higher preferences or lower expectations will lead to lower preferences. In this study, it is suggested that if consumers are not certain about the performance expectations of the new product, this uncertainty will lead them to have lower preferences.

Thus, the fourth hypothesis is proposed:

Hypothesis 4a: Lower degrees of categorization confidence for the new product will result in a less favorable brand attitude.

Hypothesis $4 \mathrm{~b}$ : Lower degrees of categorization confidence for the new product will result in lower levels of purchase intention.

\section{Research Methodology}

\section{Participants and Experimental Design}

Three hundred and fifty undergraduate and graduate students of various disciplines from a major university participated in the study. 51 percent of the participants were male and 49 percent were female.

The hypotheses in the study were tested with a single experiment. In order to test the hypotheses category decision is manipulated with a 2 (soft drink schema ad with no label indicated-alcoholic drink schema ad with no label indicated) $\times 2$ (soft drink schema ad with soft drink label indicated-alcoholic drink schema ad with alcoholic drink label indicated) between-groups design. Four different print ads were created to test the hypotheses. In order to determine the design and copy of the ads, several pretests were run.

40 pretest subjects were asked to indicate the attributes they thought were relevant to (1) soft drinks, and to (2) alcoholic drinks. They were also asked to describe the occasions and places in which they would prefer a soft drink and an alcoholic drink.

Refreshing, delighting, quenches thirst, gives me energy, tastes good, good with meals, healthy, good for digestion, eases the stomach came up as the most frequently mentioned attributes for soft drinks.

As for alcoholic drinks, "relaxes", "helps socializing", "helps me to overcome my anxiety", "entertaining", "gives pleasure" were the most frequently given descriptions.

When asked where to drink these two types of beverages, participants indicated that soft drinks were good with fast food and with meals in general, were more suitable to drink during day time with friends, preferred at the cafes, helps you cool off in hot weather and on the beach. Alcoholic drinks were told to be better at parties, when going out with friends at night, on romantic occasions with the loved one, and at celebrations.

As a third and final question, the respondents are asked what they would write if they were to run a print ad for a soft drink and another ad for an alcoholic drink. This question aims to better understand what type of attributes they associate with these beverages and to ensure that the content in the ads will form the appropriate soft drink or alcoholic drink schemas. Most of the taglines created by respondents emphasized the refreshing aspect of soft drinks. The respondents came up with taglines such as "refresh yourself" or "the cool refreshing taste". The taglines for alcoholic drinks accentuate the entertaining side of alcoholic drinks as "enjoying a party with friends" was a common theme in the taglines. After the answers are analyzed and attributes are classified as the ones belonging to soft drinks and the ones belonging to alcoholic drinks, a 
second judge who was an associate professor in marketing coded the answers and came up with confirming results (Interjudge reliability 96 percent).

In the making of the advertisements, the pictures and wordings chosen for the ads were based on the findings from the pretests. The four advertisement designs were as follows:

For the soft drink schema - no label condition, a picture of friends eating lunch at a restaurant was depicted with the ad copy reading "friendship moments with cider" and below "enjoy the meals with the refreshing taste of apple." A picture of two cider bottles appeared at the center. (See Figure 1 in the Appendix).

For the soft drink schema with soft drink label condition, the ad was very similar to the first one. It had the same picture and the same copy. Only this time ad copy was written with smaller fonts, and the product category was indicated with big fonts as "Cider your new soft drink with apple taste." (See Figure 2 in the Appendix).

For the alcoholic drink schema- no label condition, the advertisement showed a drawing of a group of people, especially focusing on a girl in the middle. They are dancing at a place that resembled a night club. The ad copy said "entertaining moments with cider" and below "have fun with the pleasurable taste of apple" was written. A picture of two cider bottles could be seen at the center of the advertisement. (See Figure 3 in the Appendix).

The alcoholic drink schema with alcoholic drink label condition advertisement was very similar to the previous ad. It had the same picture and the same copy. However, this time category label was indicated by big fonts as "Cider your new alcoholic drink with apple taste." (See Figure 4 in the Appendix).

At the bottom of all four advertisements, it was indicated that the product contained 3 percent alcohol.

Another pretest $(n=55)$ revealed no significant difference between the four advertisements in terms of subjects' evaluation of the ad, attitude toward the ad, and perceived effectiveness of the ad. (Repeated measure ANOVAS; all p's > 0.05)

\section{Experiment Design and Dependent Variables}

Depending on the manipulation group (soft drink or alcoholic drink), the first ad (activating soft drink schema without providing any label or activating alcoholic drink schema without providing any label) was shown. The participants were asked to fill out the perceived category and category confidence measures.

Perceived categorization was measured by asking participants which section of the supermarket (soft drink section or alcoholic drink section) they would look for if they were buying cider. (Moreau, Markman and Lehmann, 2001).

Categorization confidence was measured on a two-item, seven-point scale (Iyengar and Lepper, 2000). Participants were asked how confident they were on their categorization decision (1- not confident at all, 7very confident) and whether they felt that they were well-informed about the decision (1- not informed at all, 7- very well informed).

After completing a filler task, second advertisements with product labels indicated were shown to participants and they were asked once again to complete the categorization and categorization confidence questions. Subjects were also asked to fill out performance expectation questions, attitude towards cider, and purchase intention measures. Performance expectation questions aimed to better understand how cider was categorized in participants' minds. These items measured what kind of benefits subjects expected from cider, where and on which occasions they would consume cider.

For the operationalization of the performance expectation items, the results of the first two pretests were used. The final performance expectation measures consisted of 3 items for each category.

For the soft drink category, these items are (Cronbach's alpha = 0, 69): (i) I drink cider to quince my thirst, (ii) I drink cider when I want something healthy, (iii) I drink cider when I eat fast food.

For the alcoholic drink category, the items were listed as (Cronbach's alpha =0, 75): (i) I drink cider at a party, (ii) I drink cider to reduce my anxiety, (iii) I drink cider when I go out at night with my friends. 
The items were evaluated on a 7 point scale ranging from I disagree completely (1) to I completely agree (7). If subjects categorized cider as a soft drink, their soft drink performance expectation scores would be higher than their alcoholic drink performance expectation scores. Likewise, subjects who categorized cider as an alcoholic drink were expected to have higher scores for alcoholic drink performance expectations than soft drink performance expectations.

Attitude towards cider was measured on a six-item seven-point scale adapted from MacKenzie, Lutz, and Belch, (1986). The respondents were asked whether cider was attractive (7) or not attractive (1); very interesting (7) or not at all interesting (1); very good (7) or very bad (1); favorable (7) or unfavorable (1); nice (7) or not nice (1); appealing (7) or unappealing (1).

Purchase intention was measured by asking participants whether they would buy cider or not on a sevenpoint scale. (7- Definitely Buy, 1- Definitely Not Buy)

After the participants completed attitude towards product and purchase intention questions they were given a second filler task about their TV program choices. All ads were shown for about 30 seconds and the whole experiment took approximately 20 minutes.

\section{Data Analysis and Findings}

The results gathered from the first set of advertisements support the first hypothesis that when faced with a new product, consumers would categorize the new product in the direction of the cue provided in the advertisement and away from other categorizations. Of all the participants in the soft drink manipulation group, 63 percent of them categorized cider as an alcoholic drink as opposed to 37 percent who categorized it as a soft drink after the first ad. After the second ad, where the soft drink label was indicated, the percentage of the participants who categorized cider as an alcoholic drink reduced to 42 percent, and the percentage of subjects who categorized it as a soft drink increased to 58 percent.

Of the participants in the alcoholic drink manipulation group, 72 percent categorized cider as an alcoholic drink, compared to 28 percent who categorized it as a soft drink after seeing the first ad. After the second ad, which displayed an alcoholic label, the percentage of the participants categorizing cider as an alcoholic drink rose to 96 percent while the percentage of participants who categorized cider as a soft drink fell to 4 percent.

Table 1. Crosstabulation Results of Categorization Decisions of Soft Drink Manipulation Group Before and After Soft Drink Label is Shown

\begin{tabular}{llccc}
\hline & & \multicolumn{3}{c}{ Categorization Decision } \\
\hline & & categorized as soft drink & $\begin{array}{c}\text { categorized as } \\
\text { alcoholic drink }\end{array}$ & Total \\
\hline Label not shown & $\begin{array}{l}\text { Count } \\
\text { \% within }\end{array}$ & 63 & 107 & 170 \\
& $\begin{array}{l}\text { Label_not_Shown } \\
\text { \% of Total }\end{array}$ &, 4 &, 6 & 1,0 \\
& Count &, 2 & 73 & 173 \\
\hline $\begin{array}{l}\text { After label is } \\
\text { shown }\end{array}$ & 100 & 7 & 1,0 \\
& $\begin{array}{l}\text { \% within } \\
\text { Label_Shown } \\
\text { \% of Total }\end{array}$ &, 6 &, 4 &, 5 \\
\hline
\end{tabular}

Notes: Chi square $=14,796, \mathrm{p}=0.00$.

For subjects who were exposed to advertisements depicting cider as an alcoholic drink, the results are shown in Table 2: 
Table 2. Crosstabulation Results of Categorization Decisions of Alcoholic Drink Manipulation Group Before and After Alcoholic Drink Label is Shown

\begin{tabular}{llccc}
\hline & categorized as soft drink & $\begin{array}{c}\text { categorized as } \\
\text { alcoholic drink }\end{array}$ & Total \\
\hline Label not shown & $\begin{array}{l}\text { Count } \\
\text { \% within }\end{array}$ & 46 & 119 & 170 \\
& $\begin{array}{l}\text { Label_not_Shown } \\
\text { \% of Total }\end{array}$ &, 3 &, 7 & 1,0 \\
\hline $\begin{array}{l}\text { After label is } \\
\text { shown }\end{array}$ & Count & 6 &, 4 &, 5 \\
\hline $\begin{array}{l}\text { \% within } \\
\text { Label_Shown } \\
\text { \% of Total }\end{array}$ &, 0 & 163 & 169 \\
&, 0 & 1,0 & 1,0 \\
\hline
\end{tabular}

Notes: Chi square $=37,592, \mathrm{p}=0.00$.

The findings indicated above revealed significant results thus supported Hypothesis 1 . $\left[X^{2}(1)=14.79 p=.00\right.$ for soft drink group and $X^{2}(1)=37.59 \mathrm{p}=.00$ for alcohol group]. Providing a label to a new product enables the consumers to use the category indicated by the label to form the target representation of the new product. Furthermore, for the group exposed to the soft ad, although the information that cider contains alcohol was given, and that a more likely categorization option was present, a significant portion of the participants categorized cider as a soft drink after seeing the ad with the soft drink label. Thus, it can be concluded that consumers will categorize the new product in the direction of the explicit label provided in the advertisement and away from other more likely categorizations when they encounter a new product.

Hypothesis 2 predicted that category confidence will increase as a label was introduced. A one-way repeated measures ANOVA was performed to measure categorization confidence and the results supported this hypothesis. Category confidence scores increased significantly after the second ad. ( $M_{1}=5.44$ vs. $M_{2}=5.91 ; F_{(1}$, 349) $=37.90 ; \mathrm{p}=.000$ ).

Hypothesis 3 predicts that consumers' performance expectations of the new product will be in line with the performance of the other products that belong to the same category. Two paired samples t-test were conducted; one for participants who categorized cider as a soft drink, and another one for participants who categorized cider as an alcoholic drink.

Subjects who categorized cider as an alcoholic drink indicated significantly higher scores for alcoholic drink performance expectations $(\mathrm{M}=3.78)$ than soft drink performance expectations $(\mathrm{M}=2.65)$. $(\mathrm{t}=-8.394, \mathrm{p}<.00)$.

Although subjects who categorized cider as a soft drink reported higher scores for soft drink performance expectations $(M=3.18)$ than alcoholic drink performance expectations $(M=2.99)$, this difference was not significant ( $>$.05). Thus, we can conclude that hypothesis 3 was partially supported.

Hypothesis 4 predicted that lower levels of category confidence would induce lower levels of attitude toward the brand and purchase intention scores. Results from the data supported these hypotheses. Correlation analysis was run for category confidence, attitude toward the brand, and purchase intention scores after the second ads with labels.

Table 3. Correlations Table for Category Confidence, Attitude towards the Brand, and Purchase Intention After Category Label is Shown

\begin{tabular}{|c|c|c|c|}
\hline & $\begin{array}{l}\text { Category } \\
\text { Confidence_2 }\end{array}$ & $\begin{array}{l}\text { Attitude towards } \\
\text { brand_2 }\end{array}$ & Purchase Intention_2 \\
\hline Category Confidence_2 & 1 & & \\
\hline Attitude towards brand_2 &, $145^{* *}$ & 1 & \\
\hline Purchase Intention_2 & 087 &, $715^{* *}$ & 1 \\
\hline
\end{tabular}

Notes. ${ }^{* *} \mathrm{p}<0.01$ 
Afterward, the median scores were calculated for category confidence measures. The median score was used as a cutoff point to bisect the scores as category confidence high and category confidence low. Category confidence scores that were higher or equal to 6 were regarded as high and scores lower than 6 were regarded as low.

Independent samples t-tests were run to compare the attitude and purchase intention scores of high category confidence subjects versus low category confidence subjects after seeing the second ads with labels. Findings from the tests revealed significant results:

Table 4. Independent Samples Test Results for Attitude Towards Brand and Purchase Intention of High versus Low Confidence Subjects

\begin{tabular}{|c|c|c|c|c|c|c|}
\hline & & $\begin{array}{l}\text { Leven } \\
\text { Equal } \\
\text { Variar }\end{array}$ & $\begin{array}{l}\text { Test for } \\
\text { ff }\end{array}$ & \multicolumn{3}{|c|}{ t-test for Equality of Means } \\
\hline \multirow{3}{*}{$\begin{array}{l}\text { Attitude towards } \\
\text { Brand_2 }\end{array}$} & & $\mathrm{F}$ & Sig. & $\mathrm{t}$ & $\mathrm{df}$ & Sig. (2-tailed) \\
\hline & Equal variances assumed & 4,265 & 040 & $\begin{array}{l}- \\
2,602\end{array}$ & 346 & ,010 \\
\hline & $\begin{array}{l}\text { Equal variances not } \\
\text { assumed }\end{array}$ & & & $\begin{array}{l}- \\
2,754\end{array}$ & 233,606 & ,006 \\
\hline \multirow[t]{2}{*}{ Purchase Intention_2 } & Equal variances assumed & 1,609 & ,205 & $\begin{array}{l}- \\
1,753\end{array}$ & 348 & 081 \\
\hline & $\begin{array}{l}\text { Equal variances not } \\
\text { assumed }\end{array}$ & & & $\begin{array}{l}- \\
1,790\end{array}$ & 219,641 & 075, \\
\hline
\end{tabular}

The results gathered from these second ads indicated that the level of categorization confidence did have a significant effect on attitude towards cider and purchase intention. Subjects with higher confidence levels denoted higher scores for attitude towards cider than subjects with low confidence. (Mhigh=3.88 versus $\left.\mathrm{M}_{\mathrm{low}}=3.47, \mathrm{t}=-2.602, \mathrm{p}<.05\right)$.

The purchase intention scores of high confidence subjects are higher than the purchase intention scores of low confidence subjects, $\left(\mathrm{M}_{\mathrm{high}}=4.24\right.$ versus $\left.\mathrm{M}_{\mathrm{low}}=3.83\right)$ and this relationship is marginally significant $(\mathrm{p}=0.075)$.

\section{Discussion of Results}

\section{Categorization}

Data provided support for the hypothesis that when consumers are faced with a new product, they will categorize the new product in the direction stated by the label even if a more likely categorization exists. Previous studies demonstrated the importance of providing a label in the categorization of new products when two plausibly equal categories are present (Moreau, Markman and Lehmann 2001; Gregan-Paxton et al., 2002).

The significant relationship between soft drink label and soft drink categorization decision carries a different meaning in our study. The hypothetical cider brand in this research contains three percent alcohol which is an adequate amount to put cider into the alcoholic drink category automatically. Despite this fact, providing a soft drink label enabled a significant number of subjects to change their categorization decisions and categorize cider as a soft drink. It can be observed from the results that, of all the subjects who were exposed to soft drink advertisements, sixty-three percent of them categorized cider as an alcoholic drink as opposed to thirty-seven percent of participants who categorized it as a soft drink before the soft drink label was shown. After the label, the percentage of participants who categorized cider as an alcoholic drink decreased to forty-two, and the percentage of soft drink categorizers increased to fifty-eight. This result denotes that an alcoholic drink can be categorized as a soft drink if provided by the right cues. It can be argued that a degree of typicality exists as suggested by the probabilistic view in terms of how well an example is a cider as a soft drink (Cohen and Basu, 1987). For further research, the degree of representativeness of this particular cider (contains three percent alcohol) in the soft drink category can be investigated.

The same significant relationship is also observed in the alcoholic drink activated schema group which confirmed the results of previous research on category label. Out of all the subjects who saw the alcoholic 
advertisement, seventy-two percent categorized it as an alcoholic drink as opposed to twenty-eight percent who categorized it as a soft drink. After the label is shown, however, the percentage of alcoholic drink categorizers increased to ninety-six percent while soft drink categorizers reduced to only four percent. Thus, this result demonstrated once more how presenting a label in the advertisements leads consumers in the direction of the label.

\section{Categorization Confidence}

Data provided support for the hypothesis that when consumers are cued with a label, their categorization confidence scores will increase. Providing a label to consumers helped them to gain more confidence in their categorization decisions. In order to perform the analogy-based transfer, individuals first have to access an existing category to make extensive transfers from that domain (Gentner 1989; Moreau, Markman and Lehmann 2001). A higher degree of category confidence indicates that the access is assured and mappings from the base category can be exerted.

\section{Performance Expectations}

Hypothesis 3 suggested that consumers' performance expectations of the new product will be in line with other products in that category. This hypothesis is supported only for subjects who categorized cider as an alcoholic drink. In that group, subjects formed their performance expectations based on their categorization decisions (cider is an alcoholic drink) and evaluated the performance of cider similar to other alcoholic drinks. As analogy-based transfer suggests, when subjects were given a category label, they could make more extensive mappings from the base category to the target category. Subjects in our study accessed the familiar alcoholic drink domain with the help of the category label and transferred knowledge from that domain to the target (cider). (Gentner 1983; Gentner and Markman 1997; Moreau, Markman and Lehmann 2001).

The participants who categorized cider as a soft drink reported no significant difference in cider's expected performance as a soft drink versus as an alcoholic drink. Soft drink manipulation group participants both expected the benefits of a soft drink and an alcoholic drink from cider. The reason for this outcome can be attributed to the phrase "contains 3 percent alcohol" used in both of the soft drink ads. This statement may have acted as a second label (alcoholic drink) and enabled knowledge transfer from the alcoholic drink category as well. Past research posits that when individuals are given two plausible category labels and explicit mappings from each category they will effectively use the information from both categories. They will generate a higher level of understanding about the new product and base their performance evaluations on these two plausible categories (Moreau, Markman and Lehmann 2001). Alcoholic drink was not given as a label for the soft ad group but "contains 3 percent alcohol" statement might have functioned as a second label and although subjects categorized cider as a soft drink, they might have used the knowledge from both domains for extensive mapping and in generating performance expectations. As a result, soft drink group participants may have combined the benefits of soft drinks and alcoholic drinks at equal levels to construct their performance expectations from cider.

\section{Attitude Toward the Brand and Purchase Intention}

Data provide support for Hypothesis $4 \mathrm{a}$ and Hypothesis $4 \mathrm{~b}$, which suggested that lower degrees of category confidence will lead to lower levels of brand attitude and purchase intention. That means regardless of how they categorize cider (either as an alcoholic drink or soft drink) participants who have lower confidence in their categorization decisions will have less favorable evaluations of cider and will be less willing to buy it.

\section{Managerial Implications}

This study reveals that one of the biggest challenges facing a new product is not to be understood and categorized accurately by consumers. Individuals feel hostile towards objects that are unpredictable or incomprehensible. The participants who experienced ambiguity about the nature of cider, and had lower category confidence scores showed lower attitude scores and less willingness to try cider. It is demonstrated that when subjects cannot relate cider to an already established category in their minds, they cannot initiate the category-based transfer to further form an extensive representation of cider. This ambiguous situation leads to unfavorable product evaluations. 
When consumers face with a new product, they check their memories to make sense of that product. If no established category exists in their minds, they feel confused, and end up not liking and buying the product. Firms can help consumers by setting their marketing communications strategy accordingly. The advertisements of a new product should clearly illustrate what the product is, name the product category it belongs to, and indicate the places and occasions it can be used as well as the benefits it provides. This will help the consumers to form an accurate representation of the new product in their minds. All these efforts will facilitate the correct categorization of the new product in its initial stages and thus ensure higher product evaluations and a higher chance of trial.

Another marketing implication that can be derived from this study is the effect of categorization on consumers' consideration sets. Consideration set can be defined as the set of alternatives that the consumer considers for purchase (Alba and Chattopadhyay 1985). This study suggests that providing a category label and supplementary cues can facilitate categorization in the direction desired by the firm. Consumers form their consideration sets according to the category membership of products. For example, when a consumer decides to buy a product, his/her consideration set may most probably consist of a few brands that belong to the same product category. When a firm launches a new product, the establishment of an appropriate category may ensure inclusion in the desired consideration set. If a new product is categorized as belonging with other attractive alternatives, the chances that it will be considered for purchase will be higher than if categorized with a set of unattractive products (Sujan 1985; Sujan and Bettman 1989; Urban et al., 1993). This study demonstrates further evidence that providing a category label and endorsing it with appropriate cues can enable firms to categorize the new product in the desired category and thus increase its chances to be preferred by consumers. In the introduction stage of a new product, naming the appropriate category in the advertisements may ease the adaptation and increase sales.

\section{Limitations and Further Research}

The attributes that were used in the advertisements were determined by the findings gathered after the pretests. In the pretests, the respondents were questioned about basic alcoholic drink and soft drink categories. Different attributes could have been mentioned if participants were asked about subordinate level categories, for example, the soft alcoholic drink category. "Quench thirst" is mentioned as a defining attribute for soft drinks, and although it cannot be used for whiskey or vodka, it may be suitable for a beer or light beer. Future research may focus on specific subordinate categories to have a better understanding of category labeling, attitude formation, and performance expectations from a new product.

\section{References}

Alba, J. W., and Chattopadhyay, A. (1985). Effects of context and part-category cues on recall of competing brands. Journal of Marketing Research, 22(3), 340-349.

Alba, J. W., and Hutchinson, J. W. (1987). Dimensions of consumer expertise. Journal of Consumer Research, 13(4), 411-454.

Arboleda, A. M., and Arce-Lopera, C. (2015). Quantitative analysis of product categorization in soft drinks using bottle silhouettes. Food Quality and Preference, 45, 1-10.

Barsalou, L. W. (1983). Ad hoc categories. Memory \& Cognition, 11(3), 211-227.

Bruner, J. D., Goodnow, J. J., and Austin, G. A. (1972). Categories and cognition. Culture and Cognition, 168190.

Cider Definition (2020), www.dictionary.cambridge.org, (Erişim tarihi: 20 Ocak 2020).

Cider Statistics (2019), https://www.alliedmarketresearch.com/cider-market, (Erişim tarihi: 5 Aralık 2019).

Cohen, J. B., and Basu, K. (1987). Alternative models of categorization: Toward a contingent processing framework. Journal of Consumer Research, 13(4), 455-472. 
Dovidio, J. F., Love, A., Schellhaas, F. M., and Hewstone, M. (2017). Reducing intergroup bias through intergroup contact: Twenty years of progress and future directions. Group Processes $\mathcal{E}$ Intergroup Relations, 20(5), 606-620.

Gentner, D. (1983). Structure-mapping: A theoretical framework for analogy. Cognitive Science, 7(2), 155-170.

Gentner, D. (1989). Analogical learning. Similarity and analogical reasoning, 199.

Gentner, D., and Markman, A. B. (1997). Structure mapping in analogy and similarity. American Psychologist, 52(1), 45.

Gregan-Paxton, J., and John, D. R. (1997). Consumer learning by analogy: A model of internal knowledge transfer. Journal of Consumer Research, 24(3), 266-284.

Gregan-Paxton, J., Hibbard, J. D., Brunel, F. F., and Azar, P. (2002). "So that's what that is": Examining the impact of analogy on consumers' knowledge development for really new products. Psychology $\mathcal{E}$ Marketing, 19(6), 533-550.

Gutman, J. (1982). A means-end chain model based on consumer categorization processes. Journal of Marketing, 46(2), 60-72.

Iyengar, S. S., and Lepper, M. R. (2000). When choice is demotivating: Can one desire too much of a good thing? Journal of Personality and Social Psychology, 79(6), 995.

Lingle, J. H., Altom, M. W., and Medin, D. L. (1984). Of cabbages and kings: Assessing the extendibility of natural object concept models to social things.

Loken, B., and Ward, J. (1990). Alternative approaches to understanding the determinants of typicality. Journal of Consumer Research, 17(2), 111-126.

MacKenzie, S. B., Lutz, R. J., and Belch, G. E. (1986). The role of attitude toward the ad as a mediator of advertising effectiveness: A test of competing explanations. Journal of Marketing Research, 23(2), 130143.

Medin, D. L., Wattenmaker, W. D., and Hampson, S. E. (1987). Family resemblance, conceptual cohesiveness, and category construction. Cognitive Psychology, 19(2), 242-279.

Mela, C. F., and Lehmann, D. R. (1995). Using fuzzy set-theoretic techniques to identify preference rules from interactions in the linear model: an empirical study. Fuzzy Sets and Systems, 71(2), 165-181.

Mervis, C. B., and Rosch, E. (1981). Categorization of natural objects. Annual Review of Psychology, 32(1), 89115.

Meyers-Levy, J., and Tybout, A. M. (1989). Schema congruity as a basis for product evaluation. Journal of Consumer Research, 16(1), 39-54.

Moreau, C. P., Lehmann, D. R., and Markman, A. (2001). Entrenched category structures and resistance to really new products. Journal of Marketing Research, 38(1), 14-29.

Moreau, C. P., Markman, A. B., and Lehmann, D. R. (2001). "What is it?" Categorization flexibility and consumers' responses to really new products. Journal of Consumer Research, 27(4), 489-498.

Murphy, G. L., and Ross, B. H. (1994). Predictions from uncertain categorizations. Cognitive Psychology, 27(2), 148-193.

Rosch, E. (1999). Principles of categorization. Concepts: core readings, 189.

Shiv, B., and Fedorikhin, A. (1999). Heart and mind in conflict: The interplay of affect and cognition in consumer decision making. Journal of Consumer Research, 26(3), 278-292.

Sujan, M. (1985). Consumer knowledge: Effects on evaluation strategies mediating consumer judgments. Journal of Consumer Research, 12(1), 31-46.

Sujan, M., and Dekleva, C. (1987). Product categorization and inference making: Some implications for comparative advertising. Journal of Consumer Research, 14(3), 372-378. 
Thomas, R. D. (1998). Learning correlations in categorization tasks using large, ill-defined categories. Journal of Experimental Psychology: Learning, Memory, and Cognition, 24(1), 119.

Urban, G. L., Hulland, J. S., and Weinberg, B. D. (1993). Premarket forecasting for new consumer durable goods: Modeling categorization, elimination, and consideration phenomena. Journal of Marketing, $57(2), 47-63$.

Viswanathan, M., and Childers, T. L. (1999). Understanding how product attributes influence product categorization: development and validation of fuzzy set-based measures of gradedness in product categories. Journal of Marketing Research, 36(1), 75-94.

Weiss, L., \& Johar, G. V. (2013). Egocentric categorization and product judgment: Seeing your traits in what you own (and their opposite in what you don't). Journal of Consumer Research, 40(1), 185-201.

Ziamou, P., and Gregan-Paxton, J. (1999). Learning of new products: moving ahead by holding back. Advances in Consumer Research 26, 365-367. 
Appendix

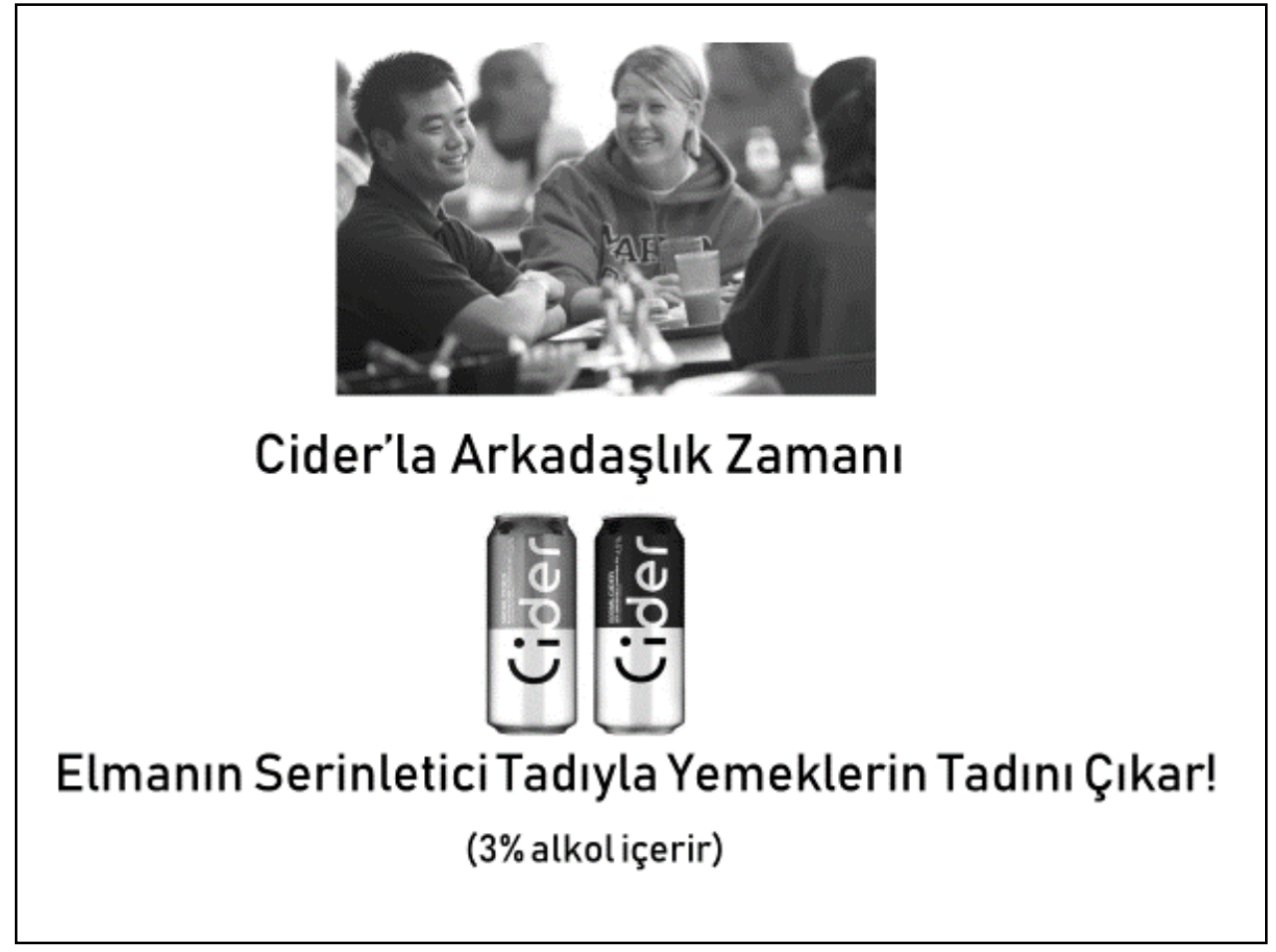

Figure 1. Ad Visual for Soft Drink Schema - No Label Condition

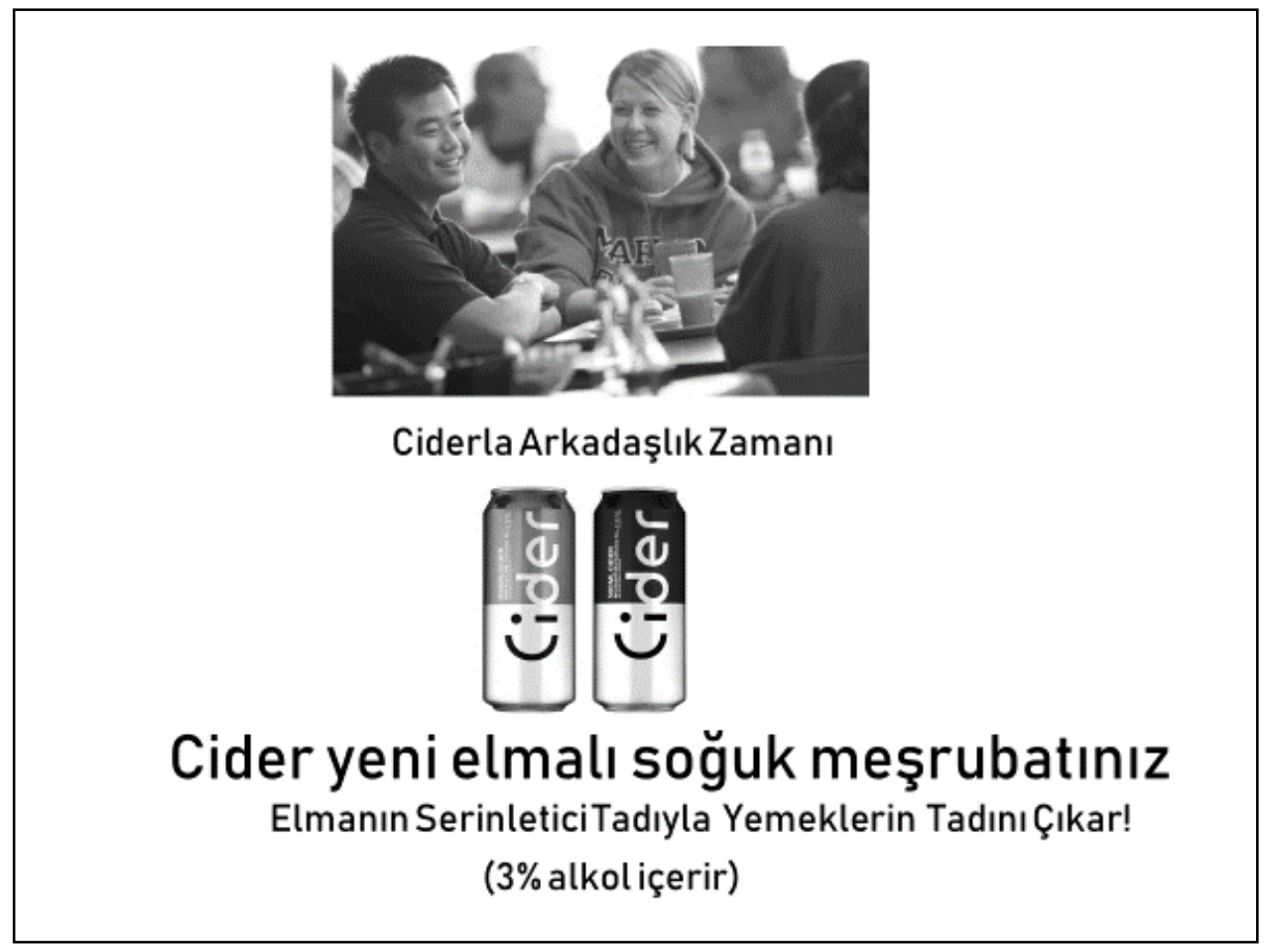

Figure 2. Ad Visual for Soft Drink Schema - Soft Drink Label Condition 


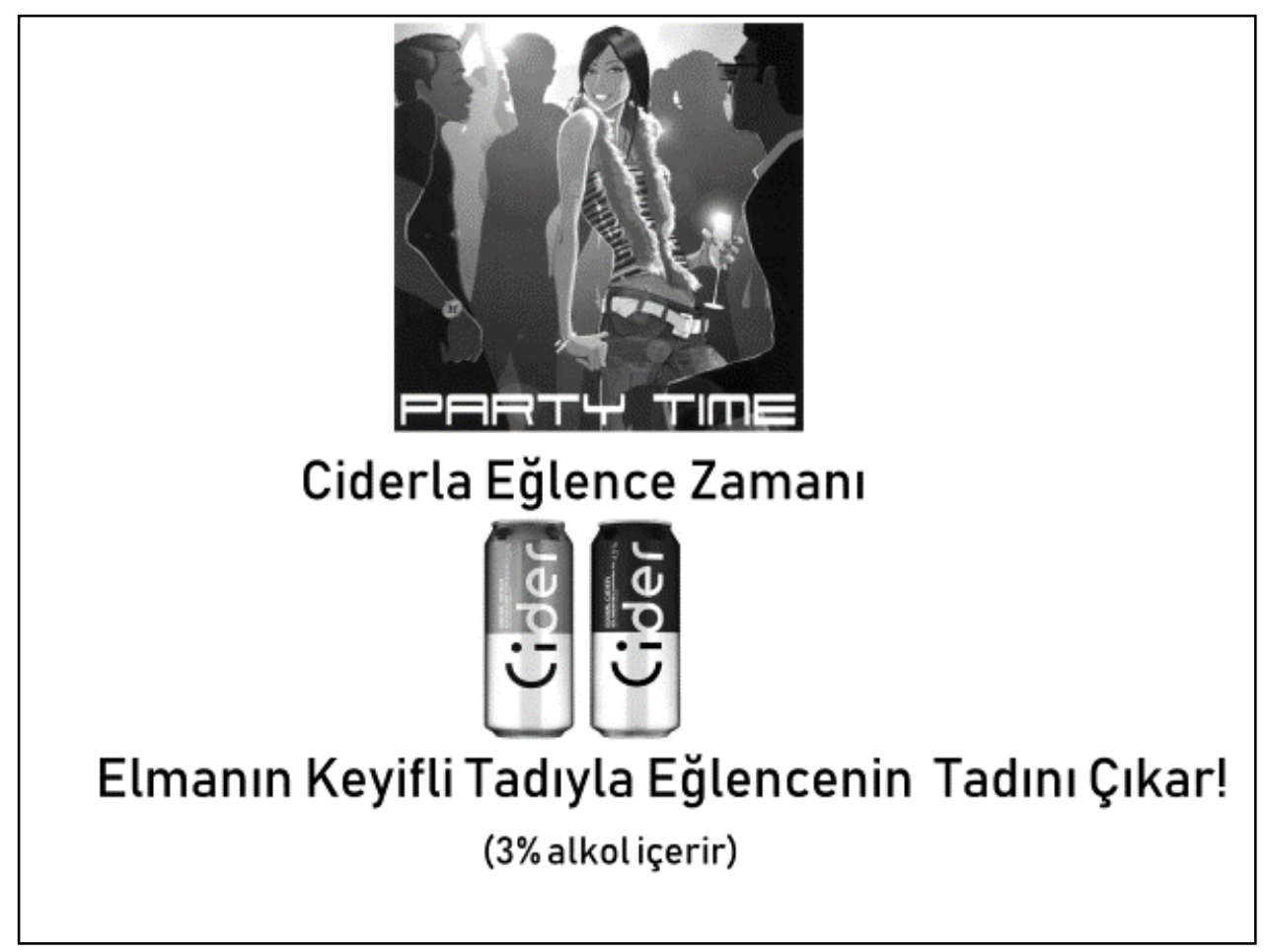

Figure 3. Ad Visual for Alcoholic Drink Schema - No Label Condition

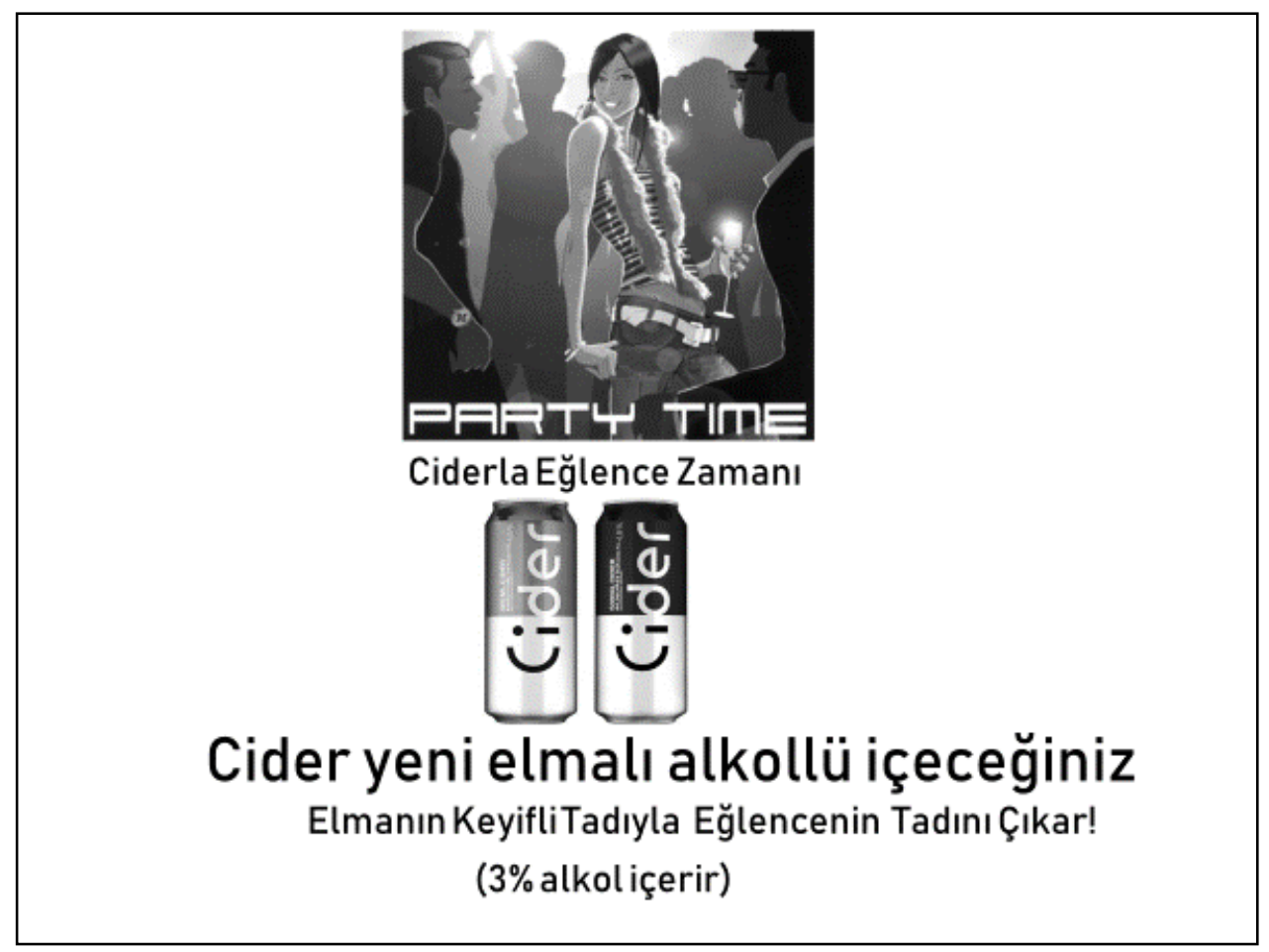

Figure 4. Ad Visual for Alcoholic Drink Schema - Alcoholic Drink Label Condition 